\title{
Microwave-treated Expandable Graphite Granule for Enhancing the Bioelectricity Generation of Microbial Fuel Cells
}

\author{
Minsoo Kim ${ }^{1}$, Young Eun Song ${ }^{1,2}$, Shuwei $\mathrm{Li}^{1}$, and Jung Rae $\mathrm{Kim}^{1 *}$ \\ ${ }^{1}$ School of Chemical Engineering, Pusan National University, Busan, 46241, Republic of Korea \\ ${ }^{2}$ Advanced Biofuel and Bioproducts Process Development Unit, Lawrence Berkeley National Laboratory, Emeryville, CA, \\ 94608, USA
}

\begin{abstract}
Microbial fuel cells (MFCs) convert chemical energy to electrical energy via electrochemically active microorganisms. The interactions between microbes and the surface of a carbon electrode play a vital role in capturing the respiratory electrons from bacteria. Therefore, improvements in the electrochemical and physicochemical properties of carbon materials are essential for increasing performance. In this study, a microwave and sulfuric acid treatment was used to modify the surface structure of graphite granules. The prepared expandable graphite granules (EGG) exhibited a 1.5 times higher power density than the unmodified graphite granules $\left(1400\right.$ vs. $\left.900 \mathrm{~mW} / \mathrm{m}^{3}\right)$. Scanning electron microscopy and Fourier transform infrared spectroscopy revealed improved physical and chemical characteristics of the EGG surface. These results suggest that physical and chemical surface modification using sulfuric acid and microwave heating improves the performance of electrode-based bioprocesses, such as MFCs.
\end{abstract}

Keywords : Microbial Fuel Cell, Expandable Graphite Granule, Microwave Oven

Received : 16 December 2020, Accepted : 24 March 2021

\section{Introduction}

Microbial fuel cells (MFCs) convert the chemical energy stored in biodegradable organics to bioelectricity via electrochemically active microorganisms [1-3]. MFCs consist of an anode chamber, where bacteria oxidize biodegradable organic matter and a cathode electrode where a reduction reaction occurs. The electrochemically active microorganisms transfer electrons to the anode electrode through biofilm formation or electron mediators. The respiratory electrons from anodic bacteria migrate to the cathode electrode via an external circuit to generate bioelectricity. Therefore, material selection for the anode is important for improving the performance and stability of MFC operations.

The anode of an MFC plays a vital role in hosting the electron transfer of bacteria. The electrode sur-

*E-mail address: j.kim@pusan.ac.kr

DOI: https://doi.org/10.33961/jecst.2020.01739

This is an open-access article distributed under the terms of the Creative Commons Attribution Non-Commercial License (http://creativecommons.org/licenses/by-nc/4.0) Attribution Non-Commercial License (http://creativecommons.org/licenses/by-nc/4.0)
which permits unrestricted non-commercial use, distribution, and reproduction in any which permits unrestricted non-commercial use, distrib
medium, provided the original work is properly cited. face also regulates the formation of electrogenic biofilms. The coulombic efficiency and electrical performance of MFCs are influenced significantly by the physical and chemical characteristics of carbon. An ideal anode material should have high electrical conductivity and specific surface area. In addition, it requires electrochemical stability, biocompatibility, and low cost for scale-up [4]. Several types of porous carbon materials have been implemented as anode electrodes, such as carbon felt, cloth, paper, and graphite granule [5-8], all of which are inexpensive and show relatively good performance in realistic MFC operating conditions. The control of porosity on the surface of such carbon materials has attracted considerable interest for MFCs.

Graphite granules have a three-dimensional porous structure and good electrical conductivity. Hence, they have been applied to packed-bed type MFCs and a range of bioreactors [9-11]. Diverse graphite granules are used widely as anode and cathode materials in MFCs as well as in wastewater treatment with biofiltration [12,13]. Unmodified graphite granules usually have low porosity and biocompatibility. 
Clogging problems have been reported as a drawback that frequently reduces the treatment efficiency, resulting in the failure of systems [14]. Structures modified with mesopores or macropores, such as carbon nanotube-sponges [15], have been evaluated to resolve these problems. On the other hand, the complicated synthesis processes and expensive materials are disadvantages.

Strong oxidizing agents, such as sulfuric acid and potassium permanganate, transform the physicochemical properties of graphite granules by increasing the surface area and electrical conductivity [16]. The surface of the treated graphite material is more porous and has higher adsorptive capacity than the untreated surface, which is favorable for biomedical applications [17]. A recent study reported that microwave radiation supplies energy to the carbon particles and increases their porosity [18].

In this study, expandable graphite granules (EGG) prepared by a combination of a sulfuric acid treatment and microwave heating process were compared with unmodified graphite granules (GG). The specific surface area and chemical characteristics of the EGG were examined by Brunauer-Emmett-Teller (BET) surface area measurements and Fourier transform infrared (FT-IR) spectroscopy, respectively. The electrochemical performance of MFCs using EGG and GG was examined by linear sweep voltammetry (LSV).

To prepare the EGG, $20 \mathrm{~g}$ of GG (diameter of 1$5 \mathrm{~mm}$, Hebei Shengsa Carbon Manufacture Trading Co., China) and $\mathrm{H}_{2} \mathrm{O}_{2}(8 \mathrm{~mL})$ were placed in a flask and stirred gently for one hour using a stirrer (HS-20, LK LABKOREA, Korea) at room temperature. $\mathrm{H}_{2} \mathrm{SO}_{4}(100 \mathrm{~mL})$ was then added slowly and stirred for $60-100$ minutes at $40^{\circ} \mathrm{C}$. The prepared carbon material was washed three times with distilled water and stored overnight at $65^{\circ} \mathrm{C}$ in an oven (LDO150F, Daihan Labtech, Korea). The modified EGG were obtained by heating the dried carbon materials in a microwave for 60 seconds [19]. All experiments were conducted in a fume hood.

Two H-Type MFCs were used, as described elsewhere [20,21]. A cylindrical stainless steel mesh $(16 \mathrm{~cm} \times 10 \mathrm{~cm})$ containing the EGG and GG $(20 \mathrm{~g}$ each) and a graphite fiber brush (No.311647, The Mill-Rose Company, USA) were used as the current collector for the EGG and GG in the anode of the MFC. Both granule materials were placed tightly around the current collector in the anode chamber to increase the contact area. Carbon felt $(3 \mathrm{~cm} \times 4 \mathrm{~cm}$, G200-2911, Fuel cell Store, USA) was used as the cathode electrode. A proton exchange membrane $\left(5 \mathrm{~cm} \times 5 \mathrm{~cm}\right.$, Nafion ${ }^{\mathrm{TM}} 117$, Fuel cell store, USA) was placed between the anode and cathode chambers. The anode and cathode electrodes were connected to an external resistance of $1000 \Omega$. The anolyte contained the following compositions: $\mathrm{CH}_{3} \mathrm{COONa}$, $3.28 \mathrm{~g} \mathrm{~L}^{-1} ; \mathrm{NH}_{4} \mathrm{Cl}, 0.23 \mathrm{~g} \mathrm{~L}^{-1} ; \mathrm{NaCl}, 0.04 \mathrm{~g} \mathrm{~L}^{-1}$; $\mathrm{MgSO}_{4} \cdot \mathrm{H}_{2} \mathrm{O}, 0.01 \mathrm{~g} \mathrm{~L}^{-1} ; \mathrm{KCl}, 0.02 \mathrm{~g} \mathrm{~L}^{-1}$; yeast extract, $0.01 \mathrm{~g} \mathrm{~L}^{-1}$. A $50 \mathrm{mM} \mathrm{K}_{3}\left[\mathrm{Fe}(\mathrm{CN})_{6}\right]$ solution in $50 \mathrm{mM}$ phosphate buffer was used as the catholyte. The inoculum was secondary anaerobic digester sludge collected from a wastewater treatment plant (Suyeong WWT Plant, Busan, Korea). The MFC reactors were operated in an incubator (SW-90S, Sangwoo, Korea) at $30^{\circ} \mathrm{C}$ in batch mode.

The surface morphology of the graphite granules was analyzed by scanning electron microscopy (SEM, VEGAII LMU, Tescan, Czech) at an acceleration voltage of $10 \mathrm{kV}$. The samples were coated with gold nanoparticles using a sputter coater (E-1010, Hitachi). FT-IR (Spectrum GX, PerkinElmer) spectroscopy in attenuated total reflection (ATR) mode was performed to examine the chemical bonding characteristics of graphite granules. The measurements were carried out over the wavenumber range, $4000-650 \mathrm{~cm}^{-1}$, with 64 scans. The surface areas were estimated using the BET method with the nitrogen adsorption/desorption isotherms (Nova 3200e system, Quantachrome Instruments, USA) over the relative pressure range $\left(\mathrm{P} / \mathrm{P}_{0}\right)$ of $0.05-0.20$.

The voltage and power generated by the MFCs were monitored using a computer-based data logging system with a data acquisition board (LabVIEW ${ }^{\mathrm{TM}}$, National Instruments ${ }^{\mathrm{TM}}$, USA), NI DAQ USB-6218, National Instruments ${ }^{\mathrm{TM}}$, USA). The polarization curves were obtained by LSV. The current $\left(\mathrm{I}_{\mathrm{V}}\right)$ and power $\left(\mathrm{P}_{\mathrm{V}}\right)$ densities were calculated using the following formula: current density $\left(I_{V}\right)=E / R V$ and power density $\left(P_{V}\right)=E I / V$, where $\mathrm{E}, \mathrm{R}, \mathrm{I}$, and $\mathrm{V}$ are the voltage output, external resistance, current, and working volume of the anode chamber $(200 \mathrm{~mL})$, respectively [22].

The granular carbon surface was modified using a sulfuric acid treatment, followed by microwave heating (Fig. 1). Sulfuric acid, a strong acid, significantly influences the physicochemical properties and porous 

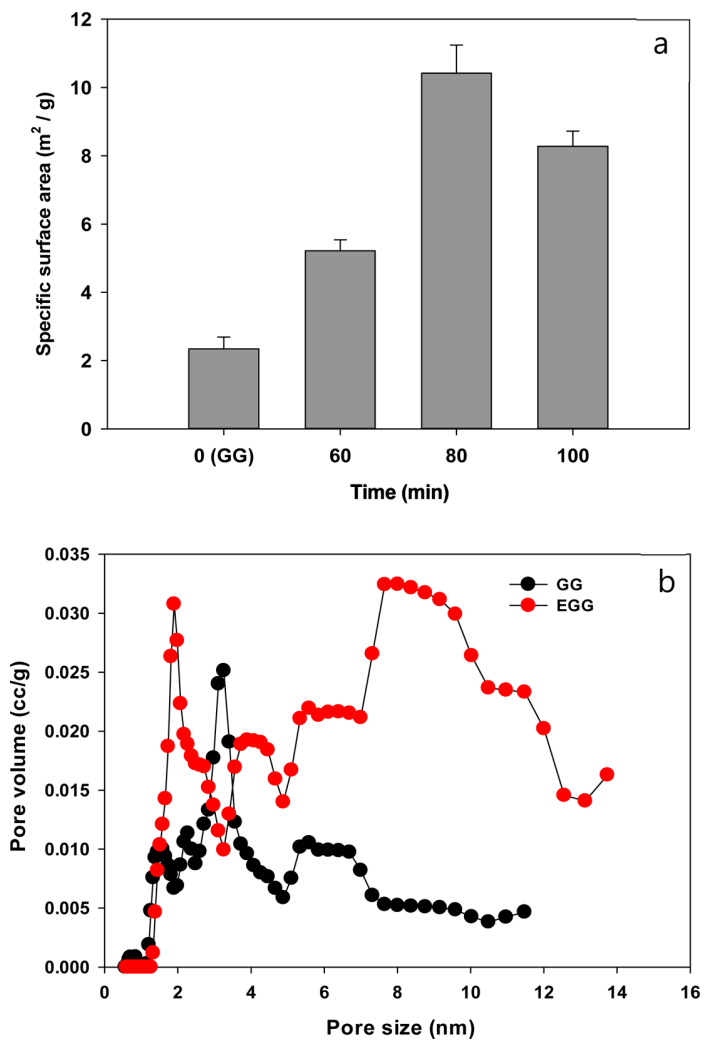

Fig. 1. Comparison of the specific surface area of the EGG and unmodified GG. (a) Effect of the stirring time with sulfuric acid, (b) pore size distribution using BET analysis.

structure of carbon surfaces [23]. Fig. 1a shows the effects of a sulfuric acid treatment on the total surface areas of EGG analyzed using the BET method. The EGG treated for $80 \mathrm{~min}$ had a specific surface area of $9.84 \mathrm{~m}^{2} / \mathrm{g}$, which was four times that of the control $\left(2.34 \mathrm{~m}^{2} / \mathrm{g}\right)$. The pore distribution of EGG showed that mesopores $(8-10 \mathrm{~nm})$ were more abundant than micropores (1-2 nm) (Fig. 1b).

The change in surface morphology and the chemical characteristics of the EGG were examined by SEM and FT-IR spectroscopy, respectively. The sulfuric acid and microwave treatment straightened the corrugated structures on the surface compared to the untreated control (Fig. 2), and transformed the pore size and arrangement on the surface. The specific surface area was increased due to the enhanced porosity of EGG, as shown in Fig. 1b. FT-IR spectroscopy characterized the vibrational frequencies of the carbon structure (Fig. 3). When a strong acid is
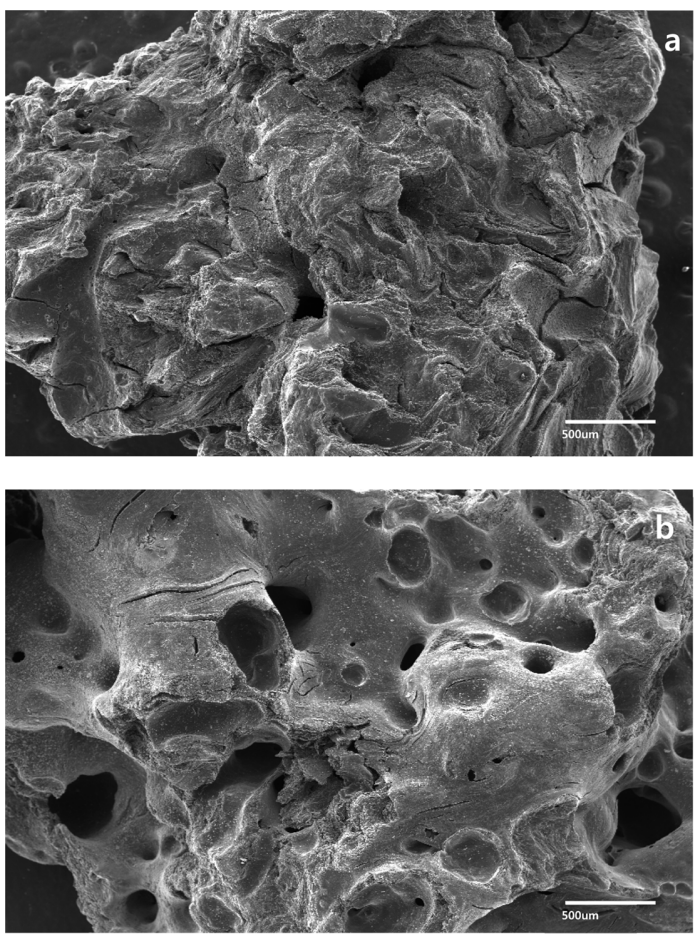

Fig. 2. Surface analysis by SEM. (a) of graphite granules, and (b) expandable graphite granules.

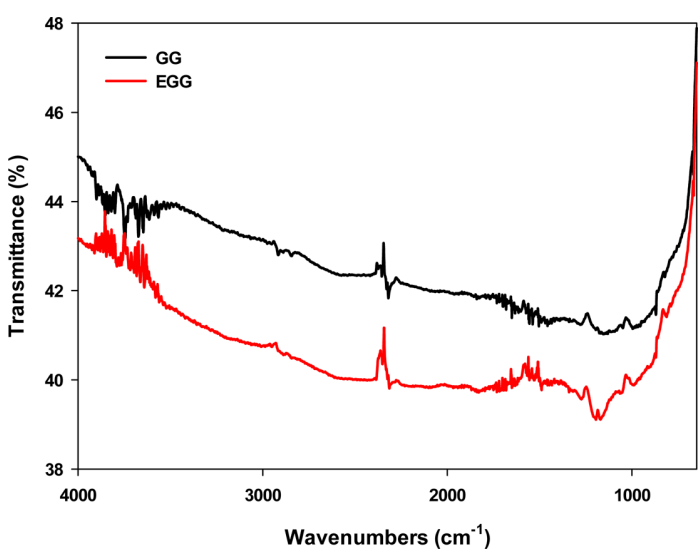

Fig. 3. FT-IR spectra of expandable graphite granules and graphite granules

intercalated into the surface of carbon granules, the carbon double bonds on the surface are oxidized with the concomitant formation of oxygen-containing groups, such as carboxylic and hydroxyl groups. Both GG and EGG showed an absorbance for the $\mathrm{C}=\mathrm{C}$ stretching vibration at $1500-1700 \mathrm{~cm}^{-1}$ and the 

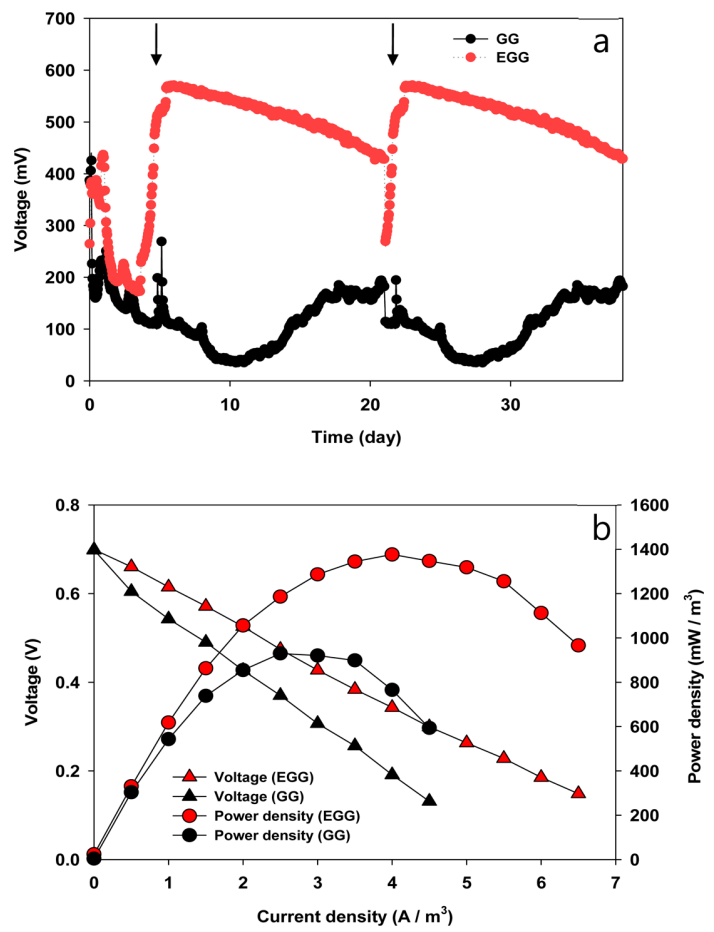

Fig. 4. Output voltage with 1000-ohm external resistance (a) and polarization curve (b) of EGG and GG. The arrows indicate that $80 \%$ of the bacterial culture was replaced with fresh medium, including acetate $40 \mathrm{mM}$.

C-C skeleton stretching vibration at $2317 \mathrm{~cm}^{-1}$. These peaks are generally found in carbon materials [2426]. On the other hand, absorbances corresponding to the $\mathrm{C}=\mathrm{O}$ stretching vibration at $1636 \mathrm{~cm}^{-1}$ and the $\mathrm{OH}$ stretching vibration at $1070 \mathrm{~cm}^{-1}$ were observed in the EGG. In addition, a C-OH stretching vibration was observed near $1169 \mathrm{~cm}^{-1}$. The $\mathrm{C}=\mathrm{O}$ and $\mathrm{OH}$ functional groups of EGG indicate that the sulfuric acid treatment may transform the chemical characteristics and the physical morphology of the carbon surface [27].

Fig. 4 a shows the bioelectricity production of a microbial fuel cell when the GG and EGG were implemented as an anode electrode. In the start-up period, the output voltage was unstable, probably due to the biological and chemical adaptation of the inoculum. The EGG showed a gradual increase in voltage from three days of operation and better power performance than the GG. The voltage of the EGG with a $1000 \mathrm{ohm}$ resistance was three times higher than that with GG (570 mV vs. $190 \mathrm{mV})$. The polarization curves in both GG and EGG after the start-up period were examined (Fig. 4b). The maximum power density produced by the EGG $\left(1400 \mathrm{~mW} / \mathrm{m}^{3}\right)$ was higher than that produced by the GG $\left(900 \mathrm{~mW} / \mathrm{m}^{3}\right)$. Overall, the biocompatibility and electron transfer between the bacteria and carbon surface are improved by modifying the surface morphology and chemical characteristics, and the bioelectricity generation of MFCs was increased.

This study examined the sulfuric acid and microwave treatment of granular graphite carbon for the anode electrode of MFCs. The prepared expandable graphite granule (EGG) showed a higher surface area and porosity than untreated carbon. The biocompatibility and the transfer of respiratory electrons from the bacteria to the electrode are improved by forming $\mathrm{C}=\mathrm{O}$ and $\mathrm{OH}$ functional groups through the above treatments. The EGG-implemented MFC showed a 1.5 times higher power density than GG-MFC (1400 vs. $900 \mathrm{~mW} / \mathrm{m}^{3}$ ). A feasible and straightforward treatment of sulfuric acid and microwave heating can increase the level of bioenergy generated from microbial fuel cells and improve the biocompatibility of carbon materials used in biofiltration and wastewater treatment.

\section{Conflict of interest statement}

On behalf of all authors, the corresponding author declares no competing financial interests or personal relationships that could have or appeared to influence the work reported in this paper.

\section{Acknowledgments}

This study was supported by a two-year research grant from Pusan National University, Korea.

\section{References}

[1] Y.E. Song, M.M. El-Dalatony, C. Kim, M.B. Kurade, B.-H. Jeon, J.R. Kim, Int. J. Hydrog. Energy., 2019, 44(4), 2372-2379.

[2] Y.E. Song, H.C. Boghani, H.S. Kim, B.G. Kim, T. Lee, B.-H. Jeon, G.C. Premier, J.R. Kim, Energies. 2017, 10(5), 596.

[3] J.R. Kim, S. Cheng, S.-E. Oh, B.E. Logan, Environ. Sci. Technol., 2007, 41(3), 1004-1009.

[4] T. Huggins, H. Wang, J. Kearns, P. Jenkins, Z.J. Ren, Bioresour. Technol., 2014, 157, 114-119. 
[5] S. Pandit, V. Patel, M. Ghangrekar, D. Das, J. Environ. Manage., 2014, 17(2-4), 252-267.

[6] Y. Yuan, S.-H. Kim, Bull Korean Chem Soc., 2008, 29(7), 1344-1348.

[7] J. Liu, Y. Qiao, C.X. Guo, S. Lim, H. Song, C.M. Li, Bioresour. Technol., 2012, 114, 275-280.

[8] Q. Deng, X. Li, J. Zuo, A. Ling, B.E. Logan, J. Power Sources., 2010, 195(4), 1130-1135.

[9] P. Aelterman, M. Versichele, M. Marzorati, N. Boon, W. Verstraete, Bioresour. Technol., 2008, 99(18), 8895-8902.

[10] M. Di Lorenzo, K. Scott, T.P. Curtis, I.M. Head, Chem. Eng. J., 2010, 156(1), 40-48.

[11] C. Kim, J.H. Lee, J. Baek, D.S. Kong, J.-G. Na, J. Lee, E. Sundstrom, S. Park, J.R. Kim, ChemSusChem. 2020, 13(3), 564-573.

[12] K. Rabaey, P. Clauwaert, P. Aelterman, W. Verstraete, Environ. Sci. Technol., 2005, 39(20), 8077-8082.

[13] P. Aelterman, K. Rabaey, H.T. Pham, N. Boon, W. Verstraete, Environ. Sci. Technol., 2006, 40(10), 33883394.

[14] K. Rabaey, L. Angenent, U. Schroder, J. Keller, Bioelectrochemical systems, IWA publishing, London, 2009.

[15] X. Xie, M. Ye, L. Hu, N. Liu, J.R. McDonough, W. Chen, H.N. Alshareef, C.S. Criddle, Y. Cui, Energy Environ. Sci., 2012, 5(1), 5265-5270.

[16] S. Lee, H. min Kim, D.G. Seong, D. Lee, Carbon. 2019, 143, 650-659.
[17] S. Wanci, W. Shizhu, C. Naizhen, Z. Lu, Z. Wei, Carbon (New York, NY). 1999, 37(2), 356-358.

[18] M.F. Veloz-Castillo, A. Paredes-Arroyo, G. VallejoEspinosa, J.F. Delgado-Jiménez, J.L. Coffer, R. González-Rodríguez, M.E. Mendoza, J. CamposDelgado, M.A. Méndez-Rojas, Can J Chem., 2020, 98(1), 49-55.

[19] J. Huang, Q. Tang, W. Liao, G. Wang, W. Wei, C. Li, Ind. Eng. Chem. Res., 2017, 56(18), 5253-5261.

[20] I. Bavasso, L. Di Palma, E. Petrucci, Chem. Eng. Trans., 2016, 47, 223-228.

[21] M.Y. Kim, C. Kim, S.K. Ainala, H. Bae, B.-H. Jeon, S. Park, J.R. Kim, Bioelectrochemistry. 2019, 125, 1-7.

[22] H.-Y. Dai, H.-M. Yang, X. Liu, X. Jian, Z.-H. Liang, ACTA METALL SIN-ENGL., 2016, 29(5), 483-490.

[23] Z. Jiang, Y. Liu, X. Sun, F. Tian, F. Sun, C. Liang, W. You, C. Han, C. Li, Langmuir. 2003, 19, 731-736.

[24] X. Han, T. Zhao, X. Gao, H. Li, Colloids and Surfaces A: Physicochemical and Engineering Aspects. 2018, 542, 1-7.

[25] B. Zhang, Y. Tian, X. Jin, T.Y. Lo, H. Cui, Materials. 2018, 11(11), 2205.

[26] Ö. Güler, S.H. Güler, V. Selen, M.G. Albayrak, E. Evin, Fuller. Nanotub. Carbon Nanostructures., 2016, 24(2), 123-127.

[27] Z. Wang, R. Qi, J. Wang, S. Qi, Ceram. Int., 2015, 41(10), 13541-13546. 